\title{
A Bell-Shaped $\mathrm{Mn}_{11} \mathrm{Gd}_{2}$ Single Molecule Magnet
}

\author{
Valeriu M. Mereacre, ${ }^{\dagger}$ Ayuk M. Ako, ${ }^{\dagger}$ Rodolphe Clérac, ${ }^{\ddagger}$ Wolfgang Wernsdorfer,,${ }^{\S}$ George Filoti, ${ }^{\top}$ Juan \\ Bartolomé, ${ }^{\mathbb{N}}$ Christopher E. Anson, ${ }^{\dagger}$ and Annie K. Powell ${ }^{*, \dagger}$ \\ ${ }^{\dagger}$ Institut für Anorganische Chemie der Universität Karlsruhe, D-76128 Karlsruhe, Germany, \\ ${ }^{*}$ Centre de Recherche Paul Pascal, CNRS-UPR 8641, 33600, Pessac, France, \\ ${ }^{\S}$ Laboratoire Louis Néel - CNRS, 38042 Grenoble Cedex 9, France, \\ "Instituto de Ciencia de Materiales de Aragon, Ciuda Universitaria, 50009-Zaragoza, Spain
}

\section{Experimental}

\section{Supporting Information}

All the reactions were carried out under aerobic conditions. Starting materials were obtained from commercial sources and used without further purification. The infrared spectra were measured using the $\mathrm{KBr}$ disk method on a Perkin Elmer Spectrum Spectrometer. Elemental analyses for $\mathrm{C}, \mathrm{H}$ and $\mathrm{N}$ were carried out at the Institute for Inorganic Chemistry at the University of Karlsruhe.

\section{Synthesis}

Compound (1) was synthesised according to modified procedure described in ref. 1.

$\left.\mathbf{M n}_{6} \mathrm{O}_{\mathbf{2}}(\mathbf{P i v})_{10}(4-\mathrm{Me}-\mathbf{p y})_{\mathbf{2 . 5}}(\mathbf{P i v H})_{1.5}\right]$ (1) A slurry of $\mathrm{Mn}(\mathrm{OAc})_{2} \cdot 4 \mathrm{H}_{2} \mathrm{O}$ (3.00 g, $\left.12.00 \mathrm{mmol}\right), \mathrm{KMnO}_{4}$ $(1.90 \mathrm{~g}, 12.00 \mathrm{mmol})$ and pivalic acid $(18.36 \mathrm{~g}, 180.00 \mathrm{mmol})$ was heated and maintained at reflux until the solution became colourless. The solution was cooled to $100^{\circ} \mathrm{C}$, then $\mathrm{MeCN}(10 \mathrm{ml})$ and $4-\mathrm{Me}-$ py $(0.6 \mathrm{ml})$ were added. The resulting mixture was again heated to boiling, then $\mathrm{MeCN}(30 \mathrm{ml})$ was added and the reaction mixture cooled to room temperature. Red-brown crystals were formed after one day. They were recrystallised from 1:1 $\mathrm{MeCN} / \mathrm{CH}_{2} \mathrm{Cl}_{2}$, filtered, washed with several portions of $\mathrm{MeCN}$, and dried in air. Yield: $5.65 \mathrm{~g}(80.5 \%$ based on $\mathrm{Mn})$. Elemental analysis calcd (\%) for $\mathrm{C}_{72.5} \mathrm{H}_{122.5} \mathrm{~N}_{2.5} \mathrm{O}_{25} \mathrm{Mn}_{6}$ (dried): $\mathrm{C} 49.51, \mathrm{H} 7.02, \mathrm{~N}$ 1.99; found: $\mathrm{C} 49.71, \mathrm{H} 7.19, \mathrm{~N}$ 1.82. IR (KBr): $\hat{0}=$ 2960 (s), 2927 (m), 1692 (m), 1618 (m), 1591 (vs), 1570 (vs), 1482 (vs), 1458 (w), 1416 (vs), 1374 (s), 1359 (s), 1319 (w), 1229 (s), 1207 (m), 1030 (w), 1013 (w), 979 (w), 936 (w), 894 (w), 804 (w), 786 (w), $725(\mathrm{w}), 612(\mathrm{~s}), 584(\mathrm{~m}), 556(\mathrm{~m}), 532(\mathrm{w}), 489(\mathrm{w}), 437 \mathrm{~cm}^{-1}(\mathrm{w})$.

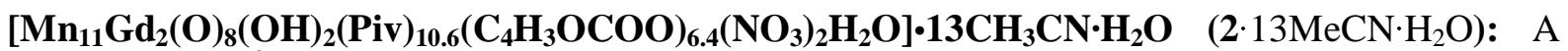

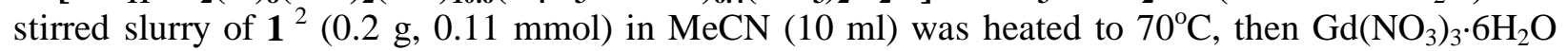
$(0.19 \mathrm{~g}, 0.45 \mathrm{mmol})$ and furoic acid $\left(\mathrm{C}_{4} \mathrm{H}_{3} \mathrm{OCOOH}\right)(0.17 \mathrm{~g}, 1.52 \mathrm{mmol})$ were added in small portions, resulting in a dark-brown solution after $20 \mathrm{~min}$. After stirring under reflux for additional $30 \mathrm{~min}$, the solution was filtered, and concentrated by slow evaporation to give dark-brown crystals after 3 days. The resulting crystals were collected by filtration, washed with $\mathrm{MeCN}$, and dried in air. Yield: $\sim 0.05 \mathrm{~g}$ (23.0\% based on $\mathrm{Mn}$ ). Elemental analysis for dried sample: calcd (\%) for $\mathrm{C}_{87} \mathrm{H}_{121.6} \mathrm{~N}_{3} \mathrm{O}_{58.4} \mathrm{Mn}_{11} \mathrm{Gd}_{2}$ (corresponds to loss of $12 \mathrm{MeCN}$ from the crystallographic formula): C 34.12, H 4.00, N 1.37; found: C 34.39, H 4.21, N 1.19. IR (KBr): v̂́ = 3454 (m), 3138 (w), 2963 (s), 2932 (s), 1581 (vs), 1558 (vs), 1537 (s), 1483 (vs), 1461 (s), 1430 (vs), 1377 (s), 1361 (s), 1281 (m), 1228 (vs), 1209 (s), 1143 (m), $1071(\mathrm{w}), 1033$ (w), 1012 (s), $979(\mathrm{w}), 937$ (m), $888(\mathrm{~m}), 795$ (m), 783 (s), 757 (m), 736 (w), 662 (vs), $624(\mathrm{vs}), 596(\mathrm{~m}), 517(\mathrm{w}), 495(\mathrm{~m}), 456 \mathrm{~cm}^{-1}(\mathrm{w})$. 


\section{Refinement of the Crystal Structure of $\left(2 \cdot 13 \mathrm{MeCN} \cdot \mathrm{H}_{2} \mathrm{O}\right)$ :}

Most of the pivalate ligands were found to show the not-unexpected two-fold disorder of their methyl groups, and one furoate ligand showed two-fold disorder between the two possible orientations of the furyl ring in the plane. One ligand was found to be a superposition of a pivalate and a furoate; in the final refinement the occupancies were set at 0.4 and 0.6, respectively. Higher thermal parameters for some pivalate and furoate $\mathrm{C}$ and $\mathrm{O}$ atoms is more likely to result from thermal motion than further unresolved disorder; any attempts to model such disorder did not improve the structure.

All ordered non-H atoms were assigned anisotropic thermal parameters. Disordered $\mathrm{C}$ and $\mathrm{O}$ atoms in pivalate or furoate ligands were refined isotropically. $\mathrm{H}$ atoms were assigned isotropic thermal parameters equal to $1.2 U_{\mathrm{eq}}$ or $1.5 U_{\mathrm{eq}}$ of the atom to which they are bonded.

Coordinates of hydroxo $\mathrm{H}$-atoms were refined; organic $\mathrm{H}$-atoms were placed in calculated positions. Disordered furoate ligands were refined as variable-metric regular pentagons. Some C-Me bond lengths in disordered pivalate groups were also restrained.

The water and one $\mathrm{MeCN}$ in the lattice were well-behaved and could be refined anisotropically. Further disordered $\mathrm{MeCN}$ molecules could be identified from Fourier difference maps but did not refine satisfactorily. These were omitted, and their electron density corrected using the squeeze option in PLATON ${ }^{3}$, accounting for 527 electrons in a solvent-accessible void in the unit cell of $1523 \AA^{3} .24$ $\mathrm{MeCN}$ (12 per cluster) correspond to 528 electrons, and the compound was therefore formulated as $2 \cdot 13 \mathrm{MeCN} \cdot \mathrm{H}_{2} \mathrm{O}$. Note that these disordered $\mathrm{MeCN}$ molecules are lost on drying (see $\mathrm{CHN}$ data, above).

1. Baikie, A.; Howes, A.; Hursthouse, M.; Quick, A.; Thornton, P. Chem. Soc., Chem. Commun. 1986, 1587.

2. The use of a similar $\mathrm{Mn}_{6}$ aggregate in reaction with $\mathrm{Ln}\left(\mathrm{NO}_{3}\right)_{3} \bullet x \mathrm{H}_{2} \mathrm{O}\left(\mathrm{Ln}=\mathrm{Gd}^{\mathrm{III}}\right.$, $\left.\mathrm{Dy}{ }^{\mathrm{III}}\right)$ in $\mathrm{CH}_{2} \mathrm{Cl}_{2} / \mathrm{CH}_{3} \mathrm{OH}$ resulted in the formation of tetranuclear species presenting a distorted butterfly core configuration: Benelli, C.; Murrie, M.; Parsons, S.; Winpenny, R. E. P. J. Chem. Soc., Dalton Trans. 1999, 4125.

3. Spek, A.L. Acta Cryst., Sect. A., 1990, A46, C34 

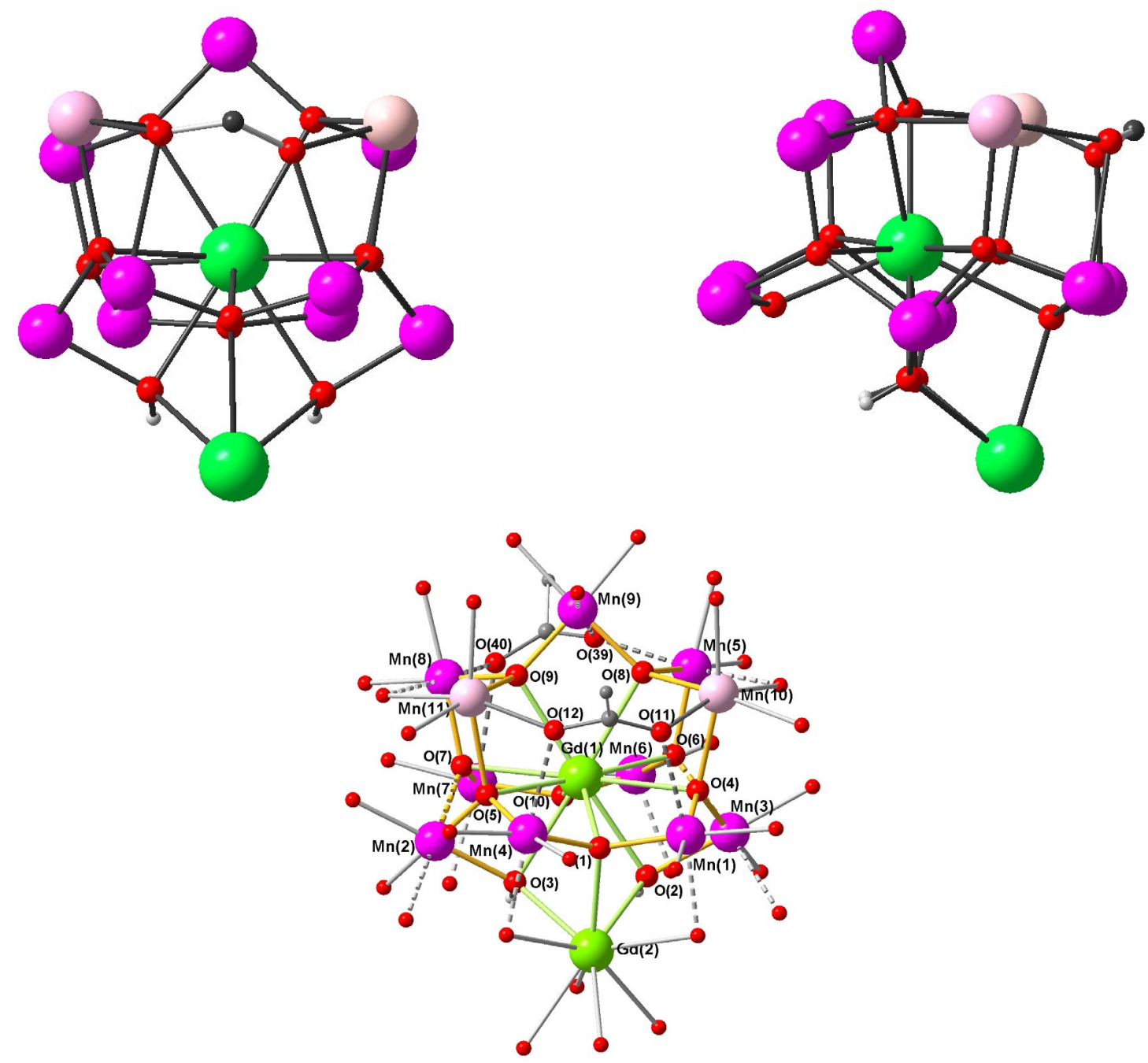

Figure S1. Core of compound 2 (in the lower picture, the $\mathrm{Mn}^{\mathrm{III}} \mathrm{Jahn}-\mathrm{Teller}$ axes are shown as dashed lines).
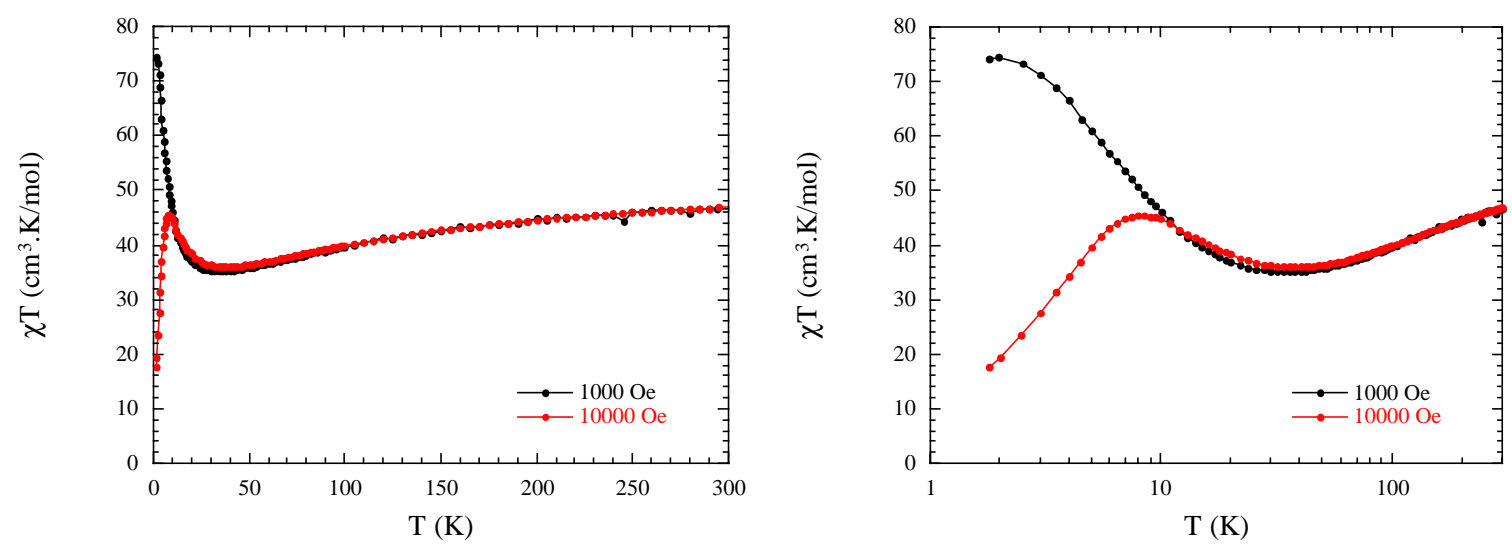

Figure S2. $\chi_{M} T$ vs $T$ plot for complex 2 in 0.1 and $1.0 \mathrm{~T}$ applied $d c$ fields. 

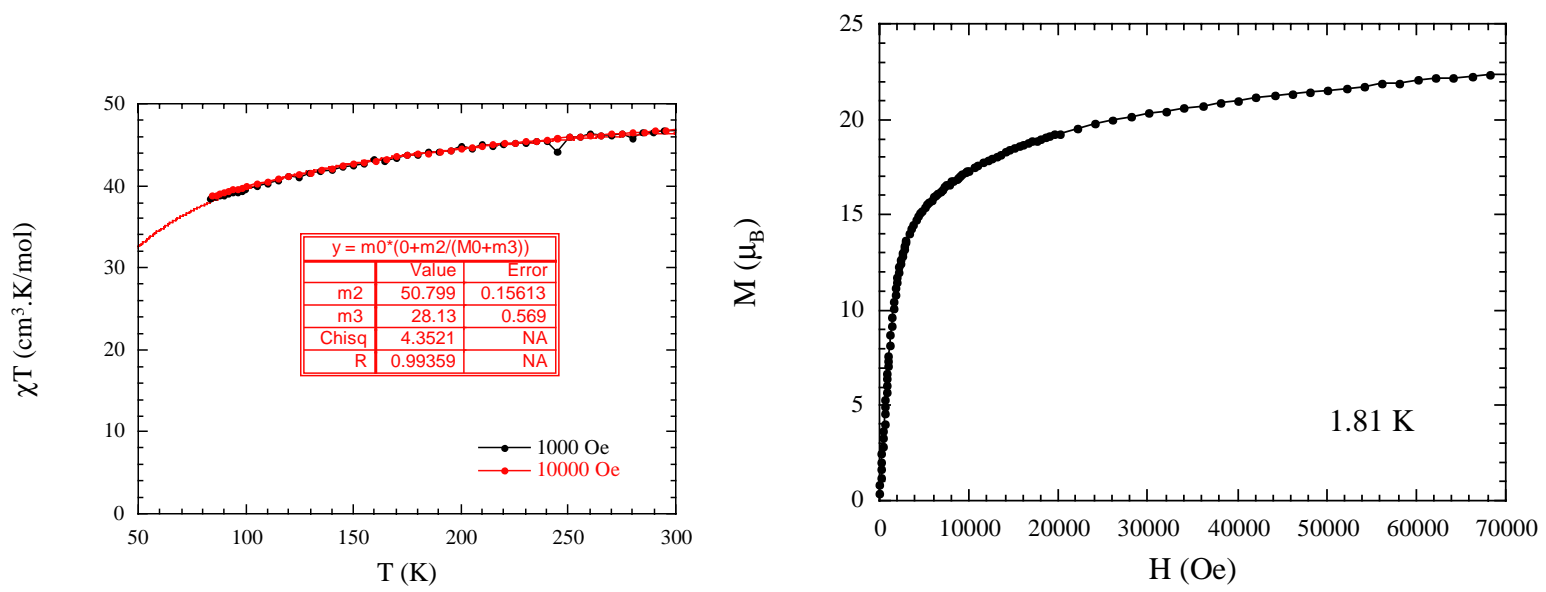

Figure S3. Left: $\chi_{M} T$ vs $T$ plot for complex 2 in 0.1 and $1.0 \mathrm{~T}$ applied $d c$ fields down to $30 \mathrm{~K}$ with its fit to a Curie Weiss law (solid line): $\mathrm{C}=50.8 \mathrm{~cm}^{3} \mathrm{~K} / \mathrm{mol}$ and $\theta=-28.1 \mathrm{~K}$; Right: Variable-field magnetization data for complex 2 at $1.81 \mathrm{~K}$.

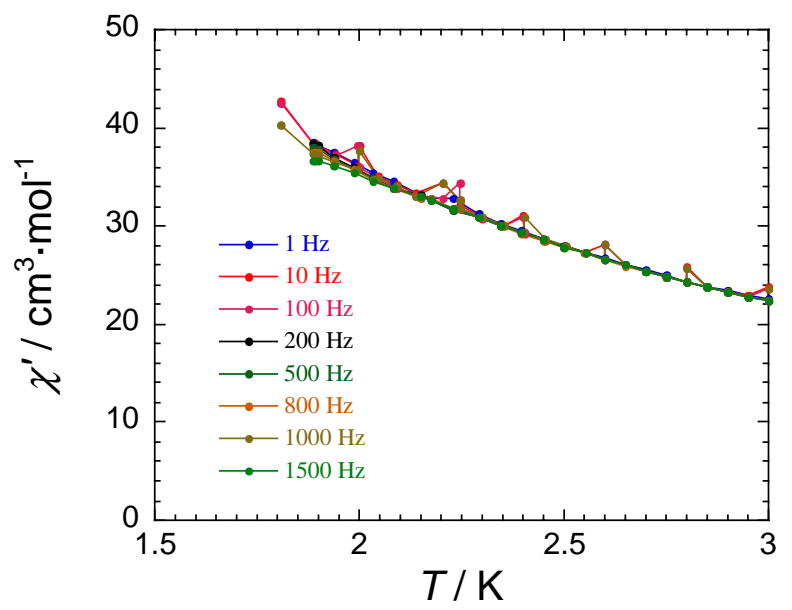

Figure S4. Plot of the in-phase $\left(\chi_{M}{ }^{\prime}\right)$ AC susceptibility signals for complex 2.

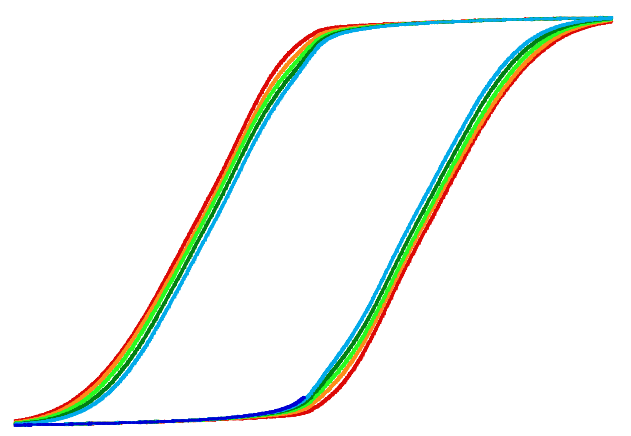

Figure S5. Magnetization $(M) v s$ applied field $\left(\mu_{0} H\right)$ at $0.4 \mathrm{~K}$ at different field sweep rates for 2. 


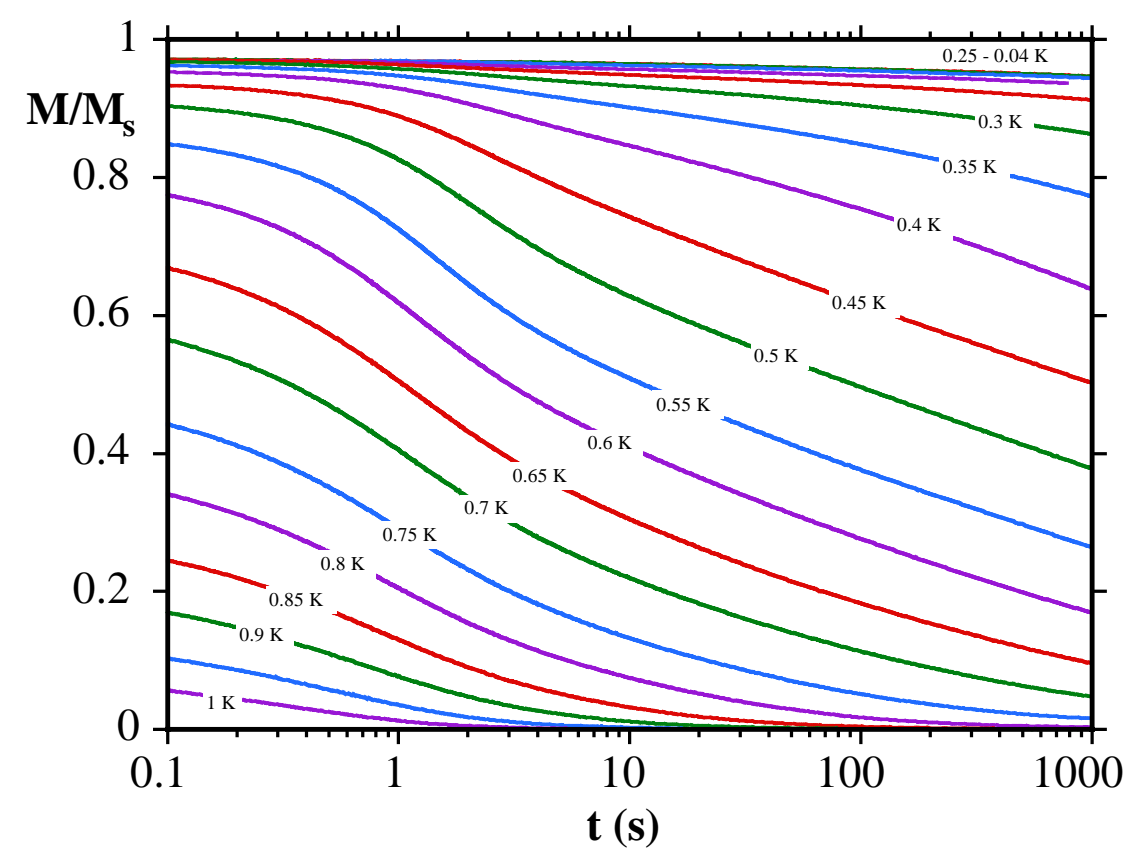

Figure S6. Magnetization decay plots for a single crystal of 2 at the indicated temperatures

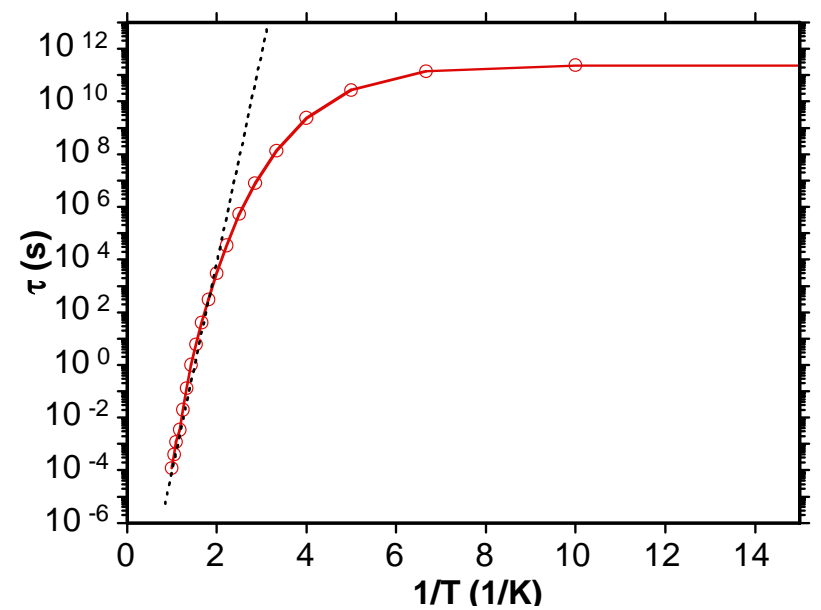

Figure S7. Arrhenius plot constructed using the data from the decay plots. $\left(\tau_{\mathrm{o}}=2 \times 10^{-12} \mathrm{~s}, U_{\text {eff }}=18 \mathrm{~K}\right)$

MicroSQUID measurements were made roughly along the easy axis although the orientation of this was not determined with respect to the molecular axis. As can be seen from figure S1, the Jahn-Teller axes of the $\mathrm{Mn}$ (III) centers are not all parallel, but the majority are oriented in the direction of the bell's vertical axis. It is likely that the Jahn-Teller distortions are the major contributors to the anisotropy. 